REVIEW ARTICLE

AFRICAN JOURNAL OF CLINICAL AND EXPERIMENTAL MICROBIOLOGY MAY 2016 ISBN 1595-689X VOL17 No.2

AJCEM/1622

COPYRIGHT 2016

AFR. J. CLN. EXPER. MICROBIOL. 17 (2): 164-167 http://dx.doi.org/10.4314/ajcem.v17i2.13

\title{
LABORATORY INFORMATION MANAGEMENT IN A CENTRAL NIGERIAN HOSPITAL: NON-COLLECTED OR UNDELIVERED REPORTS AS QUALITY INDICATOR
}

Iregbu KC.*, Abdullahi N

Department of Medical Microbiology and Parasitology, National Hospital, Abuja, P.M.B 425, Nigeria.

*Correspondence: Iregbu KC., Department of Medical Microbiology, National Hospital, Abuja. Nigeria. Email: keniregbu@yahoo.co.uk

\section{ABSTRACT}

Background: Reporting laboratory reports to the requesting physician is one vital component of the clinical laboratory testing process. Poor management of information generated in the laboratory, such as non-collection/non-delivery of test reports, can adversely affect patient care and safety.

Aim: To determine the proportion and financial impact of some laboratory test reports not collected or delivered to the requesting physician.

Methods: A review of laboratory records of requests and collected reports of malaria parasite, urine microscopy, culture and sensitivity, and blood culture from June 2014 to December 2014 was carried out, and data analyzed.

Results: A total of 5321 laboratory requests comprising 4506 malaria parasites (MP), 414 urine microscopy, culture and sensitivity (urine $\mathrm{m} / \mathrm{c} / \mathrm{s})$, and 410 blood culture were made, processed and reports generated. Of these, $1040(19.6 \%)$ were not collected or delivered to the requesting physician. Urine $\mathrm{m} / \mathrm{c} / \mathrm{s}$ with $37.9 \%(157 / 414)$ accounted for the highest test-specific non-collected reports, closely followed by blood culture with $37.7 \%(151 / 401)$ and MP with $16 \%$ (732/4506). ICU with 54.6\% (18/33) and A\&E with $21 \%(149 / 710)$ accounted for the highest department-specific non-collected or undelivered reports. The cost of all non-collected or delivered reports was N1, 442,560 or $29.3 \%$ of the cost of the total requests during the study period.

Conclusion: The proportion of non-collected or undelivered test reports as seen in this study is huge, and indicates a poor laboratory information management system. There is therefore, need to institute and implement appropriate laboratory quality management system to improve patient care and reduce wastage of resources.

Key Words: Information management, Laboratory Report, Central Nigeria

\section{GESTION DE L'INFORMATION DE LABORATOIRE DANS UN HOPITAL CENTRAL NIGERIAN: RAPPORTS NON COLLECTES OU NON LIVRES COMME INDICATEUR DE QUALITE}

Iregbu KC,* Abdullahi N.

Département de Microbiologie et Pathologie Medicale, l'hopital national, Abuja, PMB 425, Nigeria.

Correspondance :Iregbu KC., Départementde MicrobiologieMédicale, l'hôpital national Abuja, Nigeria.

Email : keniregbu@yahoo.co.uk

\section{RESUME:}

Contexte : Rapporter des rapports de laboratoire a un médecin prescripteur est une composante vitale du processus d'essais cliniques en laboratoire. La mauvaise gestion de l'information généré dans le laboratoire tel que non collection/non livres des rapports de test

Objectif : Pour déterminer la proportion et l'impact financier de certains rapports des tests de laboratoire qui ne sont pas collectés ou livrés au médecin prescripteur. 
Méthodes: Un examen des dossiers de laboratoire des demandes et des rapports collectés du parasite du paludisme, de la microscopie urine, mise en culture et antibiogramme et hémoculture du juin 2014 à décembre 2014 a été effectué et les donnéesanalysées.

Résultats : Un totale de 5321 demandes laboratoires comprenant 4506 parasites du paludisme (MP), 414 microscopie urine, mise en culture et antibiogramme (urine $\mathrm{m} / \mathrm{c} / \mathrm{s}$ ) et 410 hémoculture ont été faites, traitées et les rapports générés. De ceux - ci, 1040 $(19,6 \%)$ n'étaient pas collectés ou livrés au médecin prescripteur. L'urine $\mathrm{m} / \mathrm{c} / \mathrm{s}$ avec $37,9 \%(157 / 414)$ représentait le rapport le plus élevés non collectésspécifiques au test, suivi de près par l'hémocultureavec 37,7\% (151/401) et MP avec 16\% (732/4 506). L'unité de soins intensifs avec 54,6\% (18/33) et l'unité d'accident et d'urgence avec $21 \%$ (149/710) représentait le départementspécifique avec les rapports les plus élevés non livrés. Le coût de tous les rapports non collectés ou non livrés était N1 442560 ou $29,3 \%$ du coût des demandes totales au cours de la période d'étude.

Conclusion : La proportion des rapports des tests non collectés ou non livrés comme on le voit dans cette étude est énorme, et cela indique une mauvaise information system de gestion. Donc il est nécessaire d'instituer et de mettre en œuvre un system de gestion de laboratoire de bonne qualité et approprié pour améliorer les soins des patients et pour réduire le gaspillage des ressources.

Mots -clés : Gestion d'information, le rapport laboratoire, le Centre duNigeria.

\section{INTRODUCTION}

Clinical laboratory investigations play a crucial role in the diagnosis and treatment of diseases. Measurement of laboratory testing processes, outcomes or laboratory's contribution to patient care can be achieved via implementation of a number of quality indicators $(1,2,3)$. Among others, timely collection of laboratory reports and their delivery to the requesting physician to make an informed decision on patients' management is an important indicator of quality clinical laboratory services $(1,4)$. Failure of such reports to reach the requesting physician does not only affect the quality of patient care but also unnecessarily results in waste of financial health resources. Such non-collection/delivery of the laboratory reports may indicate ineffectiveness of the laboratory service or considerable lack of medical need for such test requests.

There is a growing need to introduce measurable and evidence based indicators of laboratory efficiency and its contribution to clinical effectiveness into every segment of the health care system $(5,6)$. Although there is paucity of literature on non-collected laboratory reports as indicator of quality laboratory information management, the few available have shown substantial numbers of noncollected/undelivered laboratory reports and the associated huge waste of laboratory budget on them $(7,8)$. There is no documented information of any study on non-collected laboratory reports in Nigeria. It is in the light of this that this novel study was conducted to determine the proportion of some types of microbiology laboratory test reports that remained non-collected by or undelivered to the requesting physicians in National Hospital Abuja

\section{METHODOLOGY}

The study was designed to determine the proportion and financial impact of laboratory reports of malaria parasites (MP), urine microscopy, culture and sensitivity (Urine $\mathrm{m} / \mathrm{c} / \mathrm{s}$ ) and blood culture investigations that were not collected from the microbiology laboratory. Laboratory data on laboratory requests by physicians from the various service department/units along with the respective non- collected reports of the same tests from June 2014 to December 2014 were retrieved from the laboratory manual information system and analysed. The direct financial impact of the non-collected reports per test type was calculated using investigations price list of microbiology laboratory. Data collected were entered into and analyzed using Microsoft Excel. Results were presented as frequencies and percentages.

\section{RESULTS}

During the study period, a total of 5321 laboratory requests for the three investigations were performed and reports produced. Of these, $1040(19.6 \%)$ were non-collected laboratory reports (Table 1). The percentage test-specific distribution of non-collected reports was as follows: Urine $\mathrm{m} / \mathrm{c} / \mathrm{s}-37.9 \%$ (157/414), Blood culture-37.7\% (151/401), and MP-16\% (732/4506) (Table 1). ICU accounted for $54.6 \%(18 / 33)$ of the department-specific distribution of all non-collected reports, while A\&E, Paediatrics, Internal medicine, GOPD, Surgery, O\&G, and others (oncology, special treatment clinic, haematology out-patient clinic, out-patient specialist clinic) constituted 21\% (149/710), $19.9 \%$ (444/2233), 17.7\% (42/237), 15.0\% (139/926), 9.9\% $(11 / 111), 9.1 \%(49 / 537)$ and $35.2 \%(188 / 537)$ respectively.

Of the non-collected MP reports based on departmentspecific request, A\&E accounted for 18.2\% (115/631), while GOPD, Paediatrics and Internal Medicine accounted for $14.7 \% \quad(135 / 918), 14.2 \% \quad(232 / 1633)$ and $12.6 \%$ (26/207) respectively (Table 1). While each of noncollected reports of urine $\mathrm{m} / \mathrm{c} / \mathrm{s}$ and blood culture constituted $69.2 \%$ of each respective test request for ICU, both were $53.3 \%$ for Internal Medicine, $50.0 \%$ for GOPD, and $42.5 \%$ and $32.7 \%$ respectively for A\&E (Tables 1).

The financial impact of all requests for all test types in this study was $\$ 4,928,020$ out of which $\$ 1,442,560$ (29.3\%) represented the cost of non-collected reports (Table 2). Non-collected MP reports accounted for $16.7 \%$ ( $344,960 / 2,066,120$ ) of the cost, urine $\mathrm{m} / \mathrm{c} / \mathrm{s} \quad 40.2 \%$ 
( $145,600 / 361,900)$ and blood culture 38.1\% (\$952,000/2,500,000) (Table 2).

TABLE1. DEPARTMENT- AND TEST- SPECIFIC DISTRIBUTIONS OF LABORATORY REQUESTS AND NON-COLLECTED REPORTS.

\begin{tabular}{|c|c|c|c|c|c|c|c|c|}
\hline \multirow[t]{2}{*}{ Department } & \multicolumn{2}{|c|}{ No of MP test } & \multicolumn{2}{|c|}{$\begin{array}{l}\text { No of urine } \mathrm{m} / \mathrm{c} / \mathrm{s} \\
\text { tests }\end{array}$} & \multicolumn{2}{|c|}{ No of blood culture tests } & \multicolumn{2}{|c|}{ Overall no (\%) of all tests } \\
\hline & Req & Non-col & Req & Non-col & Req & Non-col & Req & Non-col \\
\hline Paediatrics. & 1633 & $\begin{array}{l}232 \\
(14.2 \%)\end{array}$ & 311 & $\begin{array}{l}106 \\
(34.1 \%)\end{array}$ & 289 & $\begin{array}{l}106 \\
(36.7 \%)\end{array}$ & $\begin{array}{l}2233 \\
(42.0 \%)\end{array}$ & $444(19.9 \%)$ \\
\hline Surgery. & 89 & $\begin{array}{l}3 \\
(3.4 \%)\end{array}$ & 11 & $\begin{array}{l}4 \\
(36.1 \%)\end{array}$ & 11 & $\begin{array}{l}4 \\
(36.4 \%)\end{array}$ & $111(2.1 \%)$ & $\begin{array}{l}11 \\
(9.9 \%)\end{array}$ \\
\hline $\begin{array}{l}\text { Internal } \\
\text { Medicine. }\end{array}$ & 207 & $\begin{array}{l}26 \\
(12.6 \%)\end{array}$ & 15 & $\begin{array}{l}8 \\
(53.3 \%)\end{array}$ & 15 & $\begin{array}{l}8 \\
(53.3 \%)\end{array}$ & $237(4.5 \%)$ & $42(17.7 \%)$ \\
\hline O\&G & 531 & $\begin{array}{l}7 \\
(8.9 \%)\end{array}$ & 3 & $\begin{array}{l}1 \\
(33.3 \%)\end{array}$ & 3 & $\begin{array}{l}1 \\
(33.3 \%)\end{array}$ & $\begin{array}{l}537 \\
(10.1 \%)\end{array}$ & $\begin{array}{l}49 \\
(9.1 \%)\end{array}$ \\
\hline GOPD & 918 & $135(14.7 \%$ & 4 & $\begin{array}{l}2 \\
(50.0 \%)\end{array}$ & 4 & $\begin{array}{l}2 \\
(50.0 \%)\end{array}$ & $926(17.4 \%)$ & $139(15.0 \%)$ \\
\hline ICU & 7 & $\begin{array}{l}0 \\
(0.0 \%)\end{array}$ & 13 & $\begin{array}{l}9 \\
(69.2 \%)\end{array}$ & 13 & $\begin{array}{l}9 \\
(69.2 \%)\end{array}$ & $33(0.6 \%)$ & $18(54.6 \%)$ \\
\hline $\mathbf{A \& E}$ & 631 & $\begin{array}{l}115 \\
(18.2 \%)\end{array}$ & 40 & $17(42.5 \%)$ & 49 & $17(34.7 \%)$ & $710(13.3 \%)$ & $149(21.0 \%$ \\
\hline Others & 500 & $\begin{array}{l}174 \\
(34.8 \%)\end{array}$ & 17 & $10(58.5 \%)$ & 17 & $\begin{array}{l}4 \\
(23.5 \%)\end{array}$ & $\begin{array}{l}534 \\
(10.0 \%)\end{array}$ & $188(35.2 \%)$ \\
\hline Total & 4506 & $\begin{array}{l}732 \\
(16.0 \%)\end{array}$ & 414 & $\begin{array}{l}157 \\
(37.9 \%)\end{array}$ & 401 & $\begin{array}{l}151 \\
(37.7 \%)\end{array}$ & $5321(100 \%)$ & $1040(19.6 \%)$ \\
\hline
\end{tabular}

Req- Requested, Non-col-Non-collected, O\&G-Obstetrics and Gynaecology, GOPD-General Out-Patient Department, ICU-Intensive Care Unit, A\&E-Accident \& Emergency unit, Others-oncology, special treatment clinic, haematology out-patient clinic, out-patient specialist clinic.

TABLE 2. FINANCIAL IMPACT OF EACH AND ALL TEST TYPE(S) REQUESTS/NON-COLLECTED REPORTS

\begin{tabular}{|l|l|l|l|}
\hline Test type & Cost (\$) of total test request & $\begin{array}{l}\text { Cost (\$) of non-collected } \\
\text { results }\end{array}$ & $\begin{array}{l}\text { cost of results non- } \\
\text { collected }\end{array}$ \\
\hline MP & $2,066,120$ & 344,960 & $16.7 \%$ \\
\hline Urine m/c/s & 361,900 & 145,600 & $40.2 \%$ \\
\hline Blood culture & $2,500,000$ & 952,000 & $38.1 \%$ \\
\hline Total & $4,928,020$ & $1,442,560$ & $29.3 \%$ \\
\hline
\end{tabular}

\section{DISCUSSION}

In this study, $19.6 \%$ of the laboratory reports were not collected. This rate is higher than $2.1 \%$ and $13 \%$ reported from studies on non-collected biochemistry reports in Croatia (7) and Pakistan (8) respectively. Although reports of urine sample would appear to be the most non-collected in this study, the case of blood culture, where almost 38\% were not collected, is particularly worrisome, considering that whenever blood culture is indicated the condition is usually life-threatening. MP reports also were substantially not collected despite malaria being endemic and a major cause of morbidity and mortality especially in children.. The relatively low percentage recorded for MP test reports 
compared to others in this study might be due to the comparatively shorter turn-around time (maximum of 24 hours) for the test in our laboratory during which the illness is still largely acute and both the physician and patients have strong desires to know the result. The turn-around times for the other two tests are longer (3-5 days), during which many clinical features would have substantially abated following treatment, thus making the desire for results weaker.

ICU accounted for the highest (54.6\%) of the non-collected laboratory reports in terms of department-specific distribution, followed by A\&E. These two departments/units often deal with critically or acutely ill patients, and therefore, would have been expected to be anxious of requested clinical laboratory rest reports. ICU still recorded the highest percentage of non-collected reports $(69.2 \%)$ for each of the other two tests followed by Medicine (GOPD and A\&E .

Although this study did not look into the reasons for the non-collected reports, being essentially a laboratory based review study, it is likely the habit of some physicians ordering a barrage of necessary and un-indicated tests may be partially responsible, as they later found no need for the reports of the un-indicated tests. It could also be that reports of some of the tests had earlier been communicated across the phone and the physician felt no need for the hard

\section{REFERENCES}

1. Rico' s C, Garc1'a-Victoria M, de la Fuente B. Quality indicators and specifications for the extra-analytical phases in clinical laboratory management. Clin Chem Lab Med 2004;42:578-82.

2. Kirchner MJ, Funes VA, Adzet CB, Clar MV, Escuer MI, Girona JM, et al. Quality indicators and specifications for key processes in clinical laboratories: a preliminary experience. Clin Chem Lab Med 2007;45:672-7.

3. Simundic AM, Topic E. Quality indicators. Biochemia Medica 2008;18:311-9.

4. Plebani M. Laboratory errors: how to improve pre- and post-analytical phases? Biochemia Medica 2007;17:5-9.

5. Waise A, Plebani M. Which surrogate marker can be used to assess the effectiveness of the laboratory and its contribution to clinical outcome? Ann Clin Biochem 2001;38:589-95.

6. Lippi G, Fostini R, Guidi GC. Quality improvement in laboratory medicine: extra-analytical issues. Clin Lab Med 2008;28:285-94.

7. Simundik AM, Nikolac N, Miler M, Cipak A, Topic E. Efficiency of test report delivery to the requesting physician in an outpatient setting: an observational study. Clin Chem Lab Med 2009;47(9):1063-6. copies. In our institution patients/patients' relations and ward staff (in most cases of in-patients) come to collect the reports of laboratory tests from the laboratory, and this process may contribute to the issue of non-collected reports. Studies have widely reported inappropriate use of the clinical laboratory in clinical practice. $(9,10,11)$.

The total cost of the non-collected reports was about $29 \%$ of the total value of all the tests requested. This is higher than the $13 \%$ recorded in a similar study in Pakistan. ${ }^{8}$ This constitutes a huge economic loss to the patients who had already paid for such test. The institution also incurred some indirect costs in carrying out those tests. To determine the true cost to the institution and the real factors responsible for this high rate of non-collected results, a well designed prospective study would be required.

\section{CONCLUSION}

Information management is one of the quality system essentials, and the test report is a critical component of information from the laboratory, and represents the end product of the clinical laboratory processes with respect to testing. Therefore, the non-delivery of laboratory reports to the requesters as seen in this study is a major nonconformity and has the potential to seriously impinge on quality patient care and safety. There is therefore, need for laboratories to institute and implement appropriate quality management system.

8. Malik MF, Khan DA, Ansari WM, Khan FA. Injudicious use of laboratory facilities in tertiary care hospitals at Rawalpindi, Pakistan: a cross-sectional descriptive study. BMC Health Services Research 2013, 13:495.

9. Salvagno GL, Lippi G, Targher G, Montagnana M, Guidi GC. Monitoring glycaemic control: is there evidence for appropriate use of routine measurement of glycated haemoglobin? Clin Chem Lab Med 2007;45:1065-7.

10. Attali M, Barel Y, Somin M, Beilinson N, Shankman $\mathrm{M}$, Ackerman A, et al. A cost-effective method for reducing the volume of laboratory tests in a universityassociated teaching hospital. Mt Sinai J Med 2006;73:78794.

11. Wang TJ, Mort EA, Nordberg P, Chang Y, Cadigan $\mathrm{ME}$, Mylott L, et al. A utilization management intervention to reduce unnecessary testing in the coronary care unit. Arch Intern Med 2002;162:1885-90. 